\title{
EL SENTIMIENTO COMO FUENTE DE LIBERTAD
}

\author{
Juan Carlos Mansur*
}

\begin{abstract}
En este breve apunte hablaré de un tema que me ha tenido ocupado desde hace ya algunos años. Antes de comenzar la exposición quisiera agradecer al ITAM, particularmente al Rector Dr. Arturo Fernández, al Director de Estudios Generales, Maestro José Ramón Benito y a todos los maestros del Departamento de Estudios Generales quienes me han permitido e impulsado a desarrollar esta investigación. Agradezco también a los alumnos del IтAм con quienes he dialogado más de una vez sobre estos temas.

Quiero hacer una mención especial al Dr. Carlos McCadden y a la Dra. Milagros Mier gracias a quienes tengo la oportunidad de participar en este evento. El Dr. McCadden y yo habíamos contemplado desde el semestre pasado la necesidad de realizar un evento que conmemorara el bicentenario de la muerte de Kant, pero fue La Dra. Mier quien nos insistía en no dejar pasar la fecha de la muerte de Kant (12 de febrero) para realizarlo. Finalmente, después de un par de encuentros acordamos realizar al menos un breve homenaje para un pensador a quien admiramos profundamente.

Sobre el título que debía llevar este encuentro no encontramos otro mejor que el de Kant, filósofo de la libertad, pues si hay algo por lo que queríamos rendir nuestro tributo a este filósofo ha sido por su continuo esfuerzo de elevar la condición humana y no dejar de lado el respeto y

\footnotetext{
* Departamento Académico de Estudios Generales, ITAM.
} 


\section{JUAN CARLOS MANSUR}

dignidad que merece el hombre como espíritu libre. Fiel pensador ilustrado, Kant incita a despertar la libertad en todos los ámbitos de la actividad del ser humano, por ello no hubo más que dividir el evento en tres partes, atendiendo a las tres Críticas que escribió, y que invitan a desarrollar esta elevada vocación humana de la libertad: la libertad en el pensar, la libertad en el actuar y la libertad en el sentir, punto este último al cual me referiré en este breve escrito, no tanto con el propósito de explicar la obra de forma precisa, sino más bien con el de dar a conocer algunas reflexiones que me produce la tercera Crítica.

Antes de adentrarme en el tema del sentimiento, quisiera mencionar la relación que guardan las dos primeras Críticas con el tema de la autonomía y el de la libertad. La primera de las Críticas, titulada Crítica de la razón pura, fue escrita hacia 1781, cuando Kant contaba 57 años de edad; aunque esta obra se revela como uno de los más grandes aportes a la filosofía, su extraordinaria complejidad y aridez, así como su extensión, ocultan fácilmente los contenidos existenciales y los propósitos -que podríamos llamar humanitarios- con los que Kant escribió esta obra. La Crítica de la razón pura representa un incansable interés por explicar cómo el hombre, gracias al uso de su inteligencia, puede elevarse más allá de las sensaciones y trascender el terreno de la ignorancia y del escepticismo; es una obra que invita al hombre a realizar el esfuerzo por abandonar la pasividad de los sentidos, y ejercer activamente el entendimiento para ordenar la naturaleza. Esta enseñanza recuerda algo que dice Kant en su famoso artículo titulado ¿Qué es la Ilustración?, escrito que nos impulsa a tener el valor de pensar por nosotros mismos (Sapere Aude!) y a liberarnos de que otros piensen y tomen decisiones por nosotros. Kant nos invita a la libertad a través de la autonomía del pensar.

Además de este interés por liberar al hombre a través de la autonomía del pensar, la Crítica de la razón pura libera al hombre de los vicios de la razón: el escepticismo y el dogmatismo, y explica por qué es necesario que el hombre pose su mirada más allá incluso del terreno de las ciencias teóricas, y que interprete la naturaleza a través de las ideas suprasensibles, aun cuando de ellas no pueda nunca haber un 
conocimiento absoluto, sino análogo. Esta forma de pensar, que Kant llama idealismo trascendental busca dar vida a la razón y liberarla del escepticismo y del dogmatismo, posturas filosóficas que se especializan en cometer eutanasias de la razón, y que convierten a la filosofía en "arenas de discusiones sin fin".

Por su parte la Crítica de la razón práctica nos muestra que mediante la libertad en el actuar es posible comprender la acción del hombre más allá de los impulsos instintivo-mecánicos y explica por qué el hombre se emancipa mediante la razón, de formas que no revelan la plenitud de su ser. En efecto, mediante la no siempre bien valorada ni comprendida autonomía del imperativo categórico, Kant invita al hombre a actuar en conformidad con los ideales que su razón le propone y que le permiten respetarse a sí mismo y a los otros hombres como fines últimos, y a no tratarlos como medios. Esta capacidad de traer el reino de los fines al mundo sensible 'libera' al hombre de los impulsos de la satisfacción, el placer y el éxito, que si se toman como motores de nuestra acción, terminan por reducir la naturaleza humana a instintos o leyes mecánicas. Kant nos presenta en su moral a un hombre que logra trascender mediante la autonomía de su razón y sus ideales morales, el egoísmo que conllevan los impulsos biológicos, del éxito o de la búsqueda inmediata de la felicidad, y propone a cambio la encarnación del reino suprasensible de la libertad y de los fines entre los hombres.

En la Crítica de la razón pura y en la Crítica de la razón práctica se aprecian las dimensiones de autonomía y libertad que desarrolla el hombre en el conocer y en el actuar; resta hablar de la libertad en el sentir, tema que expone Kant en la Crítica del Juicio. En esta obra Kant explica cómo se juzga la naturaleza conforme a la finalidad. Dentro de los juicios de finalidad, Kant pone especial atención en los juicios de gusto, es decir, los juicios que califican la naturaleza como bella. Es interesante observar cómo detrás de esta explicación se alcanza a percibir también un interés en Kant por explicar que el sentimiento de belleza que produce en nosotros la naturaleza nos abre a una nueva dimensión de autonomía y libertad. Esta libertad queda definida en la 


\section{JUAN CARLOS MANSUR}

palabra contemplación, la cual es una actividad que produce un placer especial, distinto del placer que produce el agrado de las sensaciones y distinto también del sentimiento moral; la contemplación nos encamina también a mirar ‘libremente’ la naturaleza, pues al contemplar nos abstenemos de la necesidad de ordenar mediante nuestro intelecto los objetos de la naturaleza, y dejamos que nuestra imaginación y entendimiento ‘jueguen' libremente frente a las formas bellas que contemplamos.

Cuando el hombre se acerca a la naturaleza para contemplar las formas bellas que contiene, lo hace con un propósito distinto al que se tiene al buscar satisfacer en la naturaleza algún deseo o colmar intereses pragmáticos. Al acercarse a la naturaleza con el propósito de satisfacer impulsos biológicos se experimenta un placer muy distinto del placer que produce la contemplación; al placer del impulso biológico le llama Kant placer de agrado, y es el que se produce cuando vemos colmado un deseo gracias a la posesión del objeto; el comer o beber, por ejemplo, son placeres que son 'despertados’ por nuestros deseos, y desaparecen cuando poseemos lo deseado. En la contemplación de la belleza, en cambio, no hay deseo alguno de poseer. Quien contempla deja en libertad la naturaleza, pues su único deleite es admirar lo que se ve, sin otro propósito que dejar despertar un sentimiento en el espíritu.

Por otra parte, también la contemplación despierta una libertad en nosotros, pues si bien ante el agrado estamos 'encadenados' al objeto que nos proporciona el placer, y no suspendemos nuestro interés sino hasta ver colmado nuestro deseo en el objeto, en la contemplación de la belleza, en cambio, no hay deseo o interés por satisfacer nuestras necesidades o impulsos, y aprendemos a posar nuestra mirada en la naturaleza con una mirada que va más allá del interés del impulso biológico o incluso pragmático; contemplar la naturaleza es aprender a mirarla desde las regiones superiores del espíritu, por eso el sentimiento ‘eleva’ nuestra condición humana y la libera de las condiciones impulsivo-mecánicas que encierran la búsqueda de la satisfacción de agrado o pragmatismos. Por eso afirma Kant, lo bello es desinteresado.

El desinterés de la contemplación de lo bello pone al espíritu en una experiencia de libertad superior a la que se experimenta en el senti- 
miento moral. Al sentimiento moral lo experimentamos al cumplir u obedecer una norma que la razón desea y ordena, mediante conceptos, que se cumpla. Kant explica que, contrario al sentimiento moral, el puro sentimiento no se dirige por ningún concepto, por ello prescinde de toda obligación y deber, pues el placer de lo bello surge del sentimiento, y él realiza su actividad independientemente de la razón. A diferencia de la ley moral, en el sentir no estamos obligados a seguir dictámenes conceptuales; nadie puede dictar e imponer que algo guste.

De la misma manera que en el sentimiento no debe haber la imposición de concepto alguno, en la contemplación de las formas bellas nos desligamos del deseo por conocer la naturaleza y de imponerle nuestros conceptos. El conocimiento no tiene cabida en el juicio puro de gusto, pues en el sentir y contemplar nos abstraemos del interés por reglamentar y ordenar las formas bellas que contiene la naturaleza. Esto no quiere decir que en la belleza no intervenga ninguna facultad intelectual, al contrario, en la contemplación de la naturaleza hay una vivencia y actividad de nuestras facultades intelectuales, sólo que se ordenan de una forma distinta a como se ordenan en el conocer.

Ante la belleza, el entendimiento y la imaginación se liberan de la necesidad de reunir mediante leyes las formas naturales; quien contempla la naturaleza permite que la imaginación y el entendimiento ‘jueguen’ y encuentren diversas formas armónicas, sin poder aplicar nunca conceptos o reglas que expliquen esas formas que la naturaleza nos muestra, y sin tener tampoco la obligación de hacerlo. Quien se acerca a la naturaleza y encuentra en ella belleza, no podrá nunca decir a ciencia cierta, qué es exactamente lo que le place de lo que contempla; este ‘no saber qué es’ lo que nos deleita, este placer ‘inefable’ que encierra la contemplación bella, es el resultado de la capacidad de juzgar, que permite reunir de forma armónica y sin concepto, la variedad de la naturaleza, en una actividad en que se vivifican de forma siempre creciente las potencias de nuestro espíritu; esta actividad libre en la que entran nuestras facultades la percibimos como una experiencia de vida interior, y es la forma más alta de libertad a la que puede llegar el hombre, pues no hay restricción conceptual alguna que regule las 
JUAN CARLOS MANSUR

facultades, y sin embargo hay una vivencia ordenada de ellas. Quien posa su mirada en la naturaleza bella se libera de la afanosa tarea del conocimiento, y aprende a contemplar de forma reposada el mundo.

Kant nos presenta en el sentimiento una especial experiencia de libertad. La contemplación nos libera del deseo pragmático y nos eleva del nivel meramente biológico. Mediante el sentimiento levantamos nuestra mirada hacia un placer más elevado, también nos liberamos de la restricción y obligación moral que la razón impone a la voluntad y de la fatiga diaria de ordenar y conocer el mundo. Kant nos recuerda mediante su análisis del sentimiento, que el hombre está llamado a algo más que al trabajo cotidiano y que en la educación de su gusto o sentimiento existe la capacidad de acceder a las altas regiones de la libertad y vida del espíritu. Kant, como filósofo de la libertad, nos revela a través de su Crítica del juicio una nueva fuente de libertad en el hombre: la libertad en el sentir, en la cual dirige al hombre a una reconciliación con la naturaleza sin llevar más herramientas que su sentimiento, de aquí que detrás de todo sentimiento se manifieste una especial forma de autonomía en el hombre, aquella en la cual expresamos nuestro gusto o preferencia sobre ciertas obras bellas, sin plegarnos ni subordinarnos a la guía de cánones ni reglas, ni al juicio de otros, reconociendo con ello la capacidad de nuestro espíritu, de poder encontrar por sí mismo esa armonía en el universo. 